\title{
Interspecific Burrow Association in Ocypodid Crabs: Utilization of Burrows of Macrophthalmus banzai by Ilyoplax pingi
}

\author{
Keiji Wada ${ }^{\text {1) }}$, Byung Lae Choe ${ }^{2)}$ and Joongki Park ${ }^{2)}$

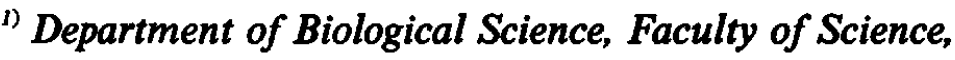 \\ Nara Women's University, Japan \\ ${ }^{2)}$ Department of Biology, Sung Kyun Kwan University, Korea
}

\begin{abstract}
A small ocypodid crab, Ilyoplax pingi, was found to cohabit with another, larger ocypodid crab, Macrophthalmus banzai, by two means: lodging in the burrows of $M$. banzai or occupying their own burrows connected with those of $M$. banzai. In the former case, the number of $I$. pingi observed emerging from a burrow of $M$. banzai was 4.0 on average and at most 16. In the latter case, the number of $I$. pingi burrows connected with one burrow of $M$. banzai was 2.8 on average and at most 10 . The main activity of $I$. pingi utilizing $M$. banzai burrows was feeding (or feeding and waving). The activity spaces of several $I$. pingi either from the same $M$. banzai burrow or from their own burrows connected with the same $M$. banzai burrow overlapped considerably. Fifteen to $28 \%$ of $I$. pingi utilizing $M$. banzai burrows began to wander within 5 min of exitting the burrow. It appears that $M$. banzai burrows are utilized by wandering $I$. pingi as temporary shelters.
\end{abstract}

Key words: ocypodid crab, burrow association, symbiosis, intertidal mud flat

\section{INTRODUCTION}

On soft sea bottoms, some burrowing animals utilize burrows made by other individuals of the same species or a different species, but there are few reports about this phenomenon. Concerning intraspecific relationships, Wada (1993) reported juvenile crabs of 4 Ilyoplax species (family Ocypodidae) dwelling in burrows of larger conspecific crabs, and Tamaki et al. (1992) found evidence that juveniles of the ghost shrimp Callianassa japonica live in branch burrows connected with an adult's larger burrow. Obligate interspecific burrow association occurs between a snapping shrimp and a gobiid fish living together in the former's burrow

Received September 4, 1996 : Accepted November 27, 1996
(Harada 1969; Karplus et al. 1972; Yanagisawa 1984). Macnae (1968) noted that burrows of the mud lobster Thalassina anomala are utilized as refuges by crabs of the genus Sesarma. Warner (1969) reported that grapsid and xanthid crabs are found in burrows of ocypodid and gecarcinid crabs in mangrove swamp. Recently, Matsumasa (personal communication) has observed that two species of Ilyoplax live in burrows of two other ocypodid species of the genera Uca and Dotillopsis.

On an intertidal mud flat in western Korea, we have found two types of burrowcohabitation by the two ocypodid species Ilyoplax pingi and Macrophthalmus banzai; one is that $I$. pingi emerges from and enters into burrows of $M$. banzai (Fig. 1A), and the other is that $I$. pingi emerges from and enters 

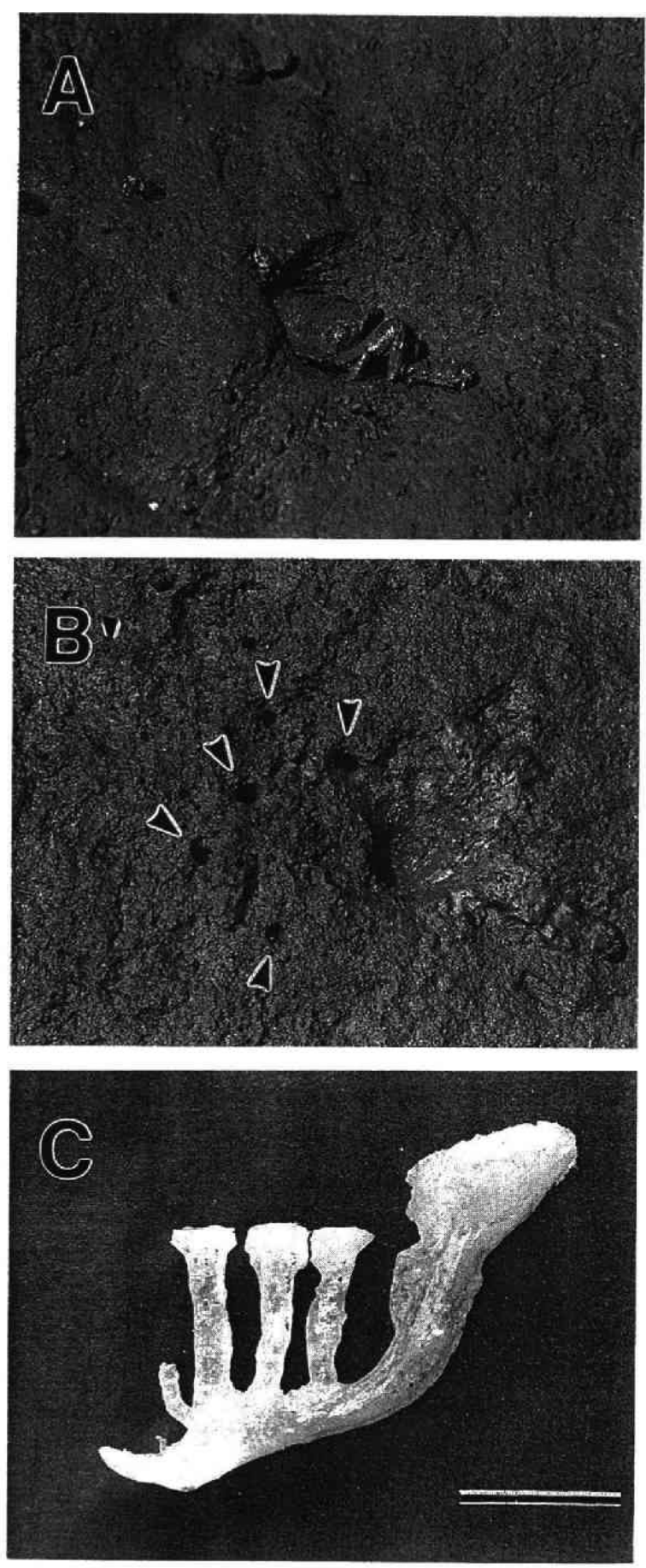

Fig. 1. Photographs showing utilization of a burrow of Macrophthalmus banzai by Ilyoplax pingi. A, Macrophthalmus banzai (the large crab) and Ilyoplax pingi (three small crabs) emerging from the former's burrow; B, openings of a burrow of Macrophthalmus banzai and five burrows (indicated by arrows) of Ilyoplax pingi connected with the former's burrow; C, a cast of three burrows of Ilyoplax pingi connected with a burrow of Macrophthalmus banzai, made of epoxy resin. Scale bar, $5 \mathrm{~cm}$. into branch burrows connected with a burrow of $M$. banzai (Figs. 1B, C). The former type is the same association as that observed by Matsumasa (personal communication), but the latter type, i.e. interspecific burrow connection, has never been reported, not only in ocypodid crabs but also in any other macrobenthic animals. This paper describes the two types of burrow-cohabitation quantitatively. In particular, the abundance, residentiality, activity space, and main activities of $I$. pingi utilizing burrows of $M$. banzai are presented.

\section{STUDY AREA AND METHODS}

All observations were conducted on the intertidal mud flat at Choji-ri, Kanghwa Island, western Korea ( $37^{\circ} 38^{\prime} \mathrm{N} 126^{\circ} 32^{\prime} \mathrm{E}$ ) in August and September, 1994. The tides there are semidiurnal with a range of $6.5-8.8 \mathrm{~m}$. The study area was established around the mid-tide level (within ca. $1 \mathrm{~m}$ above and below mean sea level), where Macrophthalmus banzai occurred with Ilyoplax pingi. The distribution of $I$. pingi extended to higher levels (to ca. $3 \mathrm{~m}$ above mean sea level). The burrow density per $50 \mathrm{~cm}$ $\times 50 \mathrm{~cm}$ (mean $\pm \mathrm{SD}$ ), obtained from two transects $(0.5 \mathrm{~m} \times 10 \mathrm{~m})$ set parallel to the shoreline at ca. $0.7 \mathrm{~m}$ above and ca. $0.3 \mathrm{~m}$ below mean sea level, was $1.1 \pm 1.1$ and $0.8 \pm 0.7$, respectively, for $M$. banzai and $6.6 \pm 3.7$ and $7.9 \pm$ 4.4, respectively, for $I$. pingi. Among randomly selected $M$. banzai burrows, the opening diameter ranged from 1.3 to $7.2 \mathrm{~cm}(\mathrm{n}=80)$ and the depth from 9 to $38 \mathrm{~cm}(\mathrm{n}=29)$. The carapace width of $M$. banzai individuals captured from randomly selected burrows ranged from 20.3 to $33.8 \mathrm{~mm}$ in males $(\mathrm{n}=12)$ and from 19.9 to 29.7 $\mathrm{mm}$ in females $(\mathrm{n}=25)$.

Hereafter, the acronym Ip-E will refer to $I$. pingi that emerge from or enter into an $M$. banzai burrow, and Ip-C to I. pingi that emerge from or enter into a burrow connected with an $M$. banzai burrow.

\section{Abundance}

The proportion of $M$. banzai burrows with Ip-E was investigated by establishing two transects parallel to the shoreline at ca. $1 \mathrm{~m}$ above (upper) and ca. $0.5 \mathrm{~m}$ below (lower) mean sea level on 23 August and 25 September. The upper 
transect measured $1 \mathrm{~m} \times 30 \mathrm{~m}$ and the lower, 1 $\mathrm{m} \times 20 \mathrm{~m}$ on 23 August, and the upper, $1 \mathrm{~m} \times 39$ $\mathrm{m}$ and the lower, $1 \mathrm{~m} \times 36 \mathrm{~m}$ on 25 September. The presence of Ip-E was scanned at each $M$. banzai burrow found in the transect by observing the burrow opening for $5 \mathrm{~min}$. at daytime low tide.

In order to learn the average and maximum numbers of Ip-E per $M$. banzai burrow, $42 M$. banzai burrows having Ip-E were selected randomly and at each burrow opening the number and the sex of Ip-E observed during $5 \mathrm{~min}$. was recorded at the daytime low tides on $11,12,13$, and 31 August.

The abundance of $I$. pingi burrows connected with those of $M$. banzai was investigated by establishing two transects parallel to the shoreline on 18 and 24 August at the same level as the above-mentioned transects. The upper transect measured $1 \mathrm{~m} \times 6 \mathrm{~m}$ and the lower, $1 \mathrm{~m} \times 3.5 \mathrm{~m}$ on 18 August, and the both $1 \mathrm{~m} \times 5.5 \mathrm{~m}$ on 24 August. For each $M$. banzai burrow found within the transect, $I$. pingi burrows within 25 $\mathrm{cm}$ were dug up to verify their connection with the $M$. banzai burrow, after measuring the distances between the $I$. pingi burrows and the $M$. banzai burrow.

Temporal fluctuations in the number of Ip-E and Ip-C were detected by counting Ip-E and Ip-C from 12 marked $M$. banzai burrows at 1-hr intervals on 21 August and by counting Ip-E from 4 marked $M$. banzai burrows at $1-\mathrm{hr}$ intervals on 26 August. The observation time for each $M$. banzai burrow was $5 \mathrm{~min}$.

\section{Surface activity}

To compare the surface activity patterns of Ip$\mathrm{E}$ and $\mathrm{Ip}-\mathrm{C}$, behavior categories except wandering observed during 5 min (feeding, feeding with waving, waving, and staying motionless) were recorded for 16 male and 33 female Ip-E and for 14 male and 23 female Ip-C.

To characterize tenacity of burrow occupation for Ip-E and Ip-C, each of 25 male and 40 female Ip-E and 25 male and 19 female Ip-C was observed for $5 \mathrm{~min}$. to check whether it began to wander.

The activity spaces of Ip-E and Ip-C were examined by recording the movements of $4 \mathrm{Ip}-\mathrm{E}$ from one $M$. banzai burrow and those of $6 \mathrm{Ip}-\mathrm{C}$ from another $M$. banzai burrow with a video camera on 19 August. From the recorded tape the movement track by each crab was plotted and the activity space was determined by outlining the track.

Observations on interactions that occurred between Ip-E and Ip-E, between Ip-C and Ip-C, between $M$. banzai and Ip-E, and between $M$. banzai and Ip-C, were made on 5 days $(32.5 \mathrm{hrs}$ in total). At each randomly selected $M$. banzai burrow, the host crab, if it emerged, and Ip-E or Ip-C from the burrow were observed for 5-15 min. When an interaction was witnessed, the sequential events were recorded together with the species and sex of the two crabs involved.

\section{RESULTS}

\section{Abundance of Ilyoplax pingi from openings of Macrophthalmus banzai burrows}

The proportion of $M$. banzai burrows with Ip-E in both the upper and the lower transects was $10.2 \%(31 / 305)$ on 23 August and $18.9 \%$ $(14 / 75)$ on 25 September. The total number of Ip-E the sex of which was determined was 27 males and 100 females, with the ratio being significantly biased toward females (test for proportion, $\mathrm{p}<0.0005)$. For $M$. banzai burrows with Ip-E, the mean number ( \pm SD) of Ip-E per $M$. banzai burrow was $4.0 \pm 3.5(\mathrm{n}=42)$, and the maximum number was 16 . The number of Ip-E from marked $M$. banzai burrows increased with emersed period on 21 August, whereas it decreased on 26 August (Fig. 2).

Abundance of $I$. pingi from burrows connected with $M$. banzai burrows

The proportion of $M$. banzai burrows connected with $I$. pingi burrows from both the upper and the lower transects was $50.0 \%$ (15 /30) on 18 August and $68.9 \%(31 / 45)$ on 24 August. For $M$. banzai burrows connected with I. pingi burrows, the mean number ( $\pm \mathrm{SD})$ of $I$. pingi burrows per $M$. banzai burrow was $2.8 \pm$ 2.0 and the maximum number was $10(n=57)$. The distance between the openings of an $M$. banzai burrow and $I$. pingi burrows connected with it ranged from 0.3 to $20.5 \mathrm{~cm}$, with the mean ( $\pm \mathrm{SD})$ being $9.4 \pm 4.8 \mathrm{~cm}(\mathrm{n}=155)$. The number of Ip-C from marked $M$. banzai burrows was largest around dead low tide on 21 August (Fig. 2). 


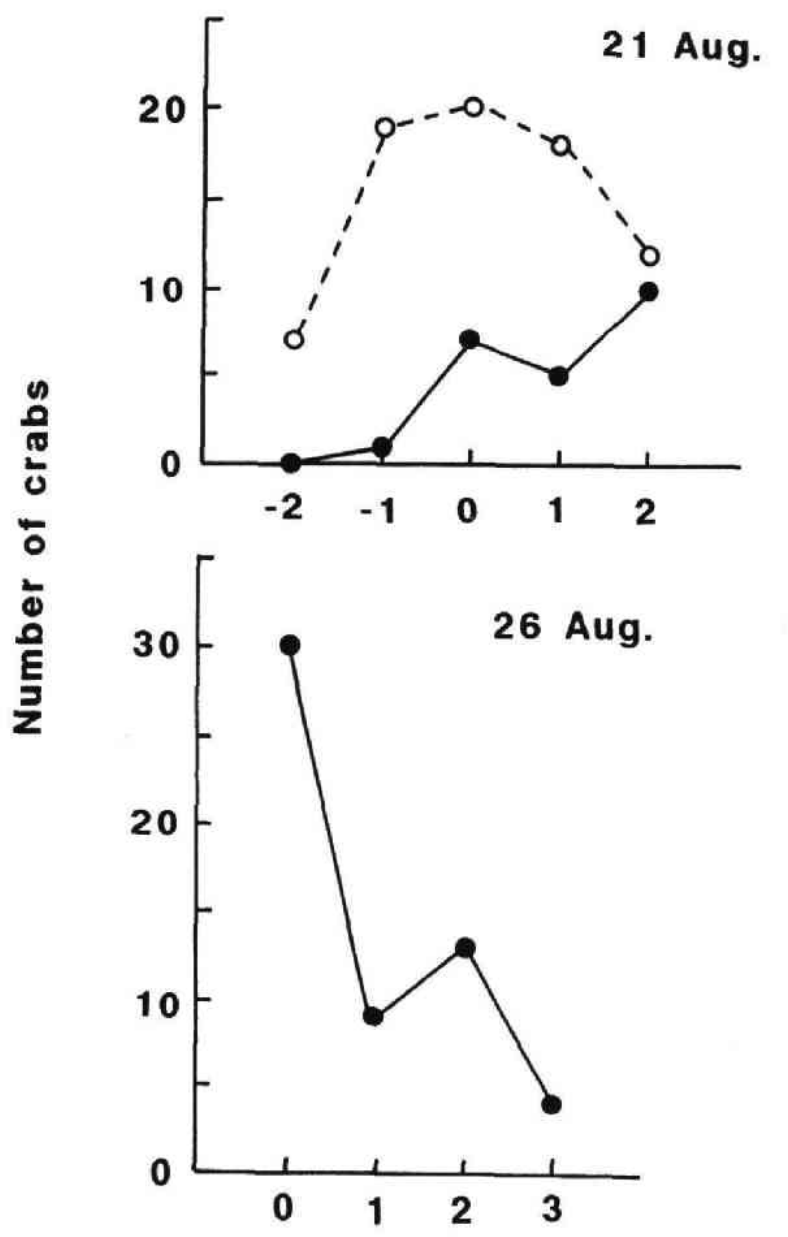

Time (hr) after dead low tide

Fig. 2. Number of Ilyoplax pingi from marked burrows of Macrophthalmus banzai, in relation to dead low tide on 21 August and 26 August, 1994. Solid circles represent I. pingi emerging from the opening of an $M$. banzai burrow, and open circles, $I$. pingi emerging from burrows connected with an $M$. banzai burrow.

Activity of $I$. pingi from openings of $M$. banzai burrows

Among 25 male and 40 female Ip-E, 7 males (28\%) and 6 females (15\%) were found to begin wandering within $5 \mathrm{~min}$, and the proportion was not significantly different between the sexes (Fisher's exact probability test, $\mathrm{p}=$ 0.85). The predominant behavior categories of Ip-E observed for 5 min were feeding and feeding with waving; 14 of 16 males and all 33 females did one or the other.

The activity spaces of Ip-E from the same $M$.

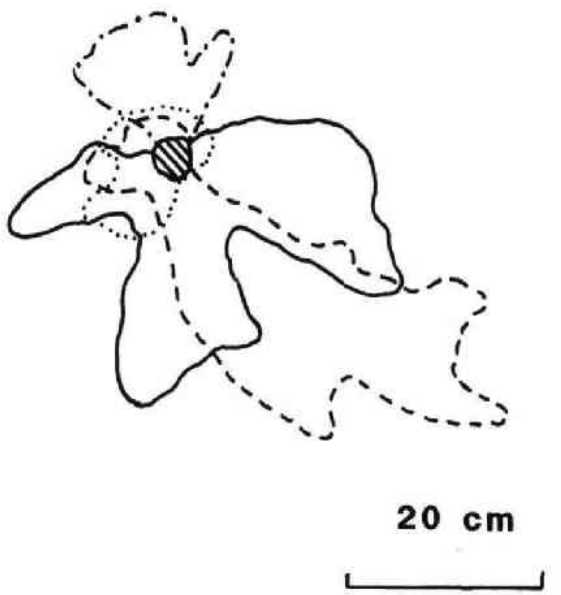

Fig. 3. Outlines of activity spaces of 4 Ilyoplax pingi (IpE) emerging from the opening of a Macrophthalmus banzai burrow (hatched area), recorded for $5 \mathrm{~min}$. The outline for each crab is represented by the same type of line.

banzai burrow overlapped each other considerably, especially near the opening of the $M$. banzai burrow (Fig. 3).

An aggressive interaction between one Ip-E and another was observed on only one occasion; a crab at the opening of the $M$. banzai burrow repelled another crab that was about to enter the burrow.

Activity of $I$. pingi from burrows connected with $M$. banzai burrows

Among 25 male and 19 female Ip-C, 6 males (24\%) and 3 females (16\%) were found to begin wandering within $5 \mathrm{~min}$, and this proportion was not significantly different between the sexes (G-test with William's correction, p > 0.2 ). The predominant behavior categories of Ip-C observed for $5 \mathrm{~min}$. were feeding and feeding with waving; 12 of 14 males and all $23 \mathrm{fe}$ males did one or the other.

The activity spaces of Ip-C from burrows connected with the same $M$. banzai burrow extended outward and overlapped each other considerably (Fig. 4).

Aggressive interactions between Ip-C crabs were observed on only two occasions; both times, a crab directed its aggressive wave toward another crab, which retreated. 


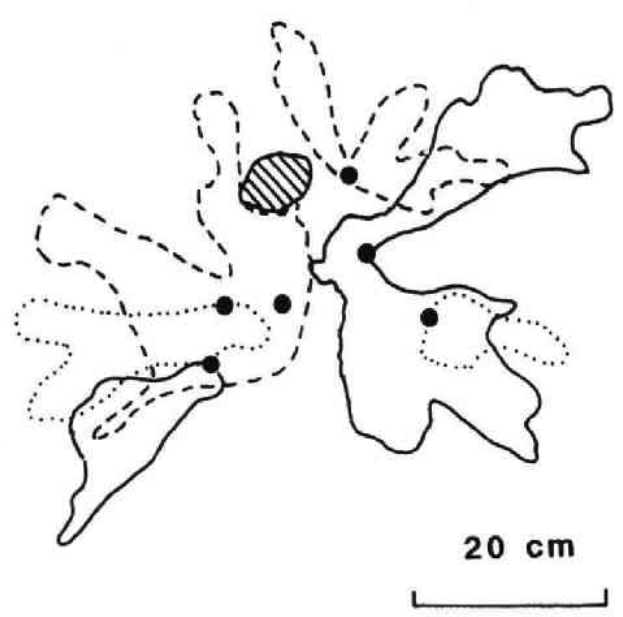

Fig. 4. Outlines of activity spaces by 6 Ilyoplax pingi (IpC) emerging from burrows (solid circles) connected with a Macrophthalmus banzai burrow (hatched area), recorded for $5 \mathrm{~min}$.

\section{Interaction between $M$. banzai and $I$. pingi}

Aggression of $M$. banzai against an Ip-E was observed on only three occasions; each time, a female $M$. banzai at the burrow opening expelled a male Ip-E by dashing or kicking it. Aggression of an Ip-E against $M$. banzai was recognized on only one occasion; a male Ip-E directed his wave toward a female $M$. banzai, which retreated. Between $M$. banzai and Ip-C no interaction was observed. Ip-E both emerged from and entered the $M$. banzai burrow either before or after the host crab.

\section{DISCUSSION}

The distribution of Ilyoplax pingi extended to a higher level in the intertidal than that of Macrophthalmus banzai; that is, $M$. banzai occurred in the lower part of the I. pingi zone. At the higher level where no $M$. banzai occurred, many $I$. pingi were found to engage in mating behavior (Wada et al. 1996), whereas no mating behavior was observed in I. pingi occurring at the lower level. The predominant behaviors recorded for $I$. pingi using $M$. banzai burrows (Ip-E and Ip-C) were feeding and feeding with waving. The proportion of Ip-E and Ip-C that began to wander within 5 min. was $15-28 \%$, which indicates their weak burrow-holding tenacity. Thus, the occurrence of $I$. pingi in the
$M$. banzai zone is for feeding while wandering and temporarily sheltering in $M$. banzai burrows. Among ocypodid crabs burrowing in intertidal flats, wandering of some population members downshore in order to forage is well known; e.g. Uca vocans (Murai et al. 1983), Uca tangeri (Ens et al. 1993), Uca pugilator (Rëinsel \& Rittschof 1995), Macrophthalmus japonicus (Henmi 1984), Scopimera globosa (Koga 1995), and Ilyoplax pusilla and I. deschampsi (Wada unpublished). Ilyoplax pingi in the Macrophthalmus zone are considered to represent another manifestation of this downwardwandering tendency of ocypodids.

The activity spaces of the several Ip-E or Ip-C from the same burrow of $M$. banzai overlapped each other quite a lot. However, aggressive interactions were scarcely observed either between Ip-E individuals or between Ip-C individuals. Consequently, both Ip-E and Ip-C are nonterritorial. The non-territoriality is a consequence of the $M$. banzai burrow being a temporary shelter and foraging not being limited to the space adjacent to the burrow.

Wandering crabs usually incur higher predation pressure than burrow- holding crabs (Ens et al. 1993). Burrows of M. banzai would benefit wandering $I$. pingi as temporary refuges. Interference by $M$. banzai against cohabiting $I$. pingi (Ip-E and Ip-C) was rarely observed when they were out of the burrow. Although $I$. pingi was almost never observed to expel $M$. banzai, many connected burrows of $I$. pingi might make the burrow of $M$. banzai less stable. In other words, $I$. pingi benefits from $M$. banzai, while $M$. banzai does not benefit from $I$. pingi, which suggests that the association is categorized as commensalism or parasitism.

Many benthic animals on soft bottoms utilize burrows as domiciles, but excavating and maintaining burrows necessitate some cost. Using burrows made by other animals relieves the cost. Burrow dependence, not only in obligate relationships such as between the alpheid shrimp and the gobiid fish (Harada 1969; Karplus et al. 1972; Yanagisawa 1984), but also in facultative relationships as found for ocypodid crabs in the present study, undoubtedly promotes coexistence of different species on the soft bottom. Such burrow association 
between species sharing the same or similar resources, like ocypodid crabs, is expected not to be uncommon in benthic animals, but the relevant informations are limited (Warner 1969; Matsumasa personal communication). Interspecific burrow association, whether obligate or facultative, should be given more attention in the study of soft bottom community organization.

\section{Acknowledgment}

We thank 3 anonymous reviewers for critical reading of the manuscript. This work was financially supported in part by Grant-in-Aid for Overseas Scientific Survey No. 06041082 from the Japan Ministry of Education, Science, Sports and Culture.

\section{REFERENCES}

Ens, B. J., M. Klaassen and L. Zwarts 1993 Flocking and feeding in the fiddler crab (Uca tangeri): prey availability as risk-taking behaviour. Netherlands Journal of Sea Research, 31: 477-494.

Harada, E. 1969 On the interspecific associations of a snapping shrimp and gobioid fishes. Publications of the Seto Marine Biological Laboratory, 16: 315-334.

Henmi, Y. 1984 The description of wandering behavior and its occurrence varying in different tidal areas in Macrophthalmus japonicus (De Haan) (Crustacea: Ocypodidae). Journal of Experimental Marine Biology and Ecology, 84: 211-224.

Karplus, I., R. Szlep and M. Tsurnamal 1972 Associative behavior of the fish Cryptocentrus cryptocentrus (Gobiidae) and the pistol shrimp Alpheus djiboutensis (Alpheidae) in artificial burrows. $\mathrm{Ma}$ rine Biology, 15: 95-104.

Koga, T. 1995 Movements between microhabitats depending on reproduction and life history in the sandbubbler crab Scopimera globosa. Marine Ecology
Progress Series, 117: 65-74.

Macnae, W. 1968 A general account of the fauna and flora of mangrove swamps and forests in the Indowest-Pacific region. Advances in Marine Biology, 6: 73-270.

Murai, M., S. Goshima and Y. Nakasone 1983 Adaptive droving behavior observed in the fiddler crab $U_{c a}$ vocans vocans. Marine Biology, 76: 159-164.

Reinsel, K. A. and D. Rittschof 1995 Environmental regulation of foraging in the sand fiddler crab $U c a$ pugilator (Bosc, 1802). Journal of Experimental Marine Biology and Ecology, 187: 269-287.

Tamaki, A., K. Ikebe, K. Muramatsu and B. Ingole 1992 Utilization of adult burrows by juveniles of the ghost shrimp, Callianassa japonica Ortmann: evidence from resin casts of burrows. Researches on Crustacea, 21: 113-120.

Wada, K. 1993 Territorial behavior, and sizes of home range and territory, in relation to sex and body size in Ilyoplax pusilla (Crustacea: Brachyura: Ocypodidae). Marine Biology, 115: 47-52.

Wada, K., B. L. Choe, J. K. Park and S. S. Yum 1996 Population and reproductive biology of Ilyoplax pingi and 1 . dentimerosa (Crustacea, Brachyura, Ocypodidae). Crustacean Research, 25: 44-53.

Warner, G. F. 1969 The occurrence and distribution of crabs in a Jamaican mangrove swamp. Journal of Animal Ecology, 38: 379-389.

Yanagisawa, Y. 1984 Studies on the interspecific relationship between gobiid fish and snapping shrimp II. Life history and pair formation of snapping shrimp Alpheus bellulus. Publications of the Seto Marine Biological Laboratory, 29: 93-116.

\section{Address}

Keiji Wada (reprint request): Department of Biological Science, Faculty of Science, Nara Women's University, Kitauoya-nishimachi, Nara 630, Japan.

Byung Lae Choe and Joongki Park: Department of Biology, Sung Kyun Kwan University, Suwon 440-746, Korea. 